\title{
Thermal Properties of Some Butadiene-Styrene Copolymers ${ }^{1}$
}

\author{
George T. Furukawa, Robert E. McCoskey, and Gerard J. King
}

\begin{abstract}
The thermal properties of $41^{\circ}$ and $122^{\circ} \mathrm{F}$ butadiene-styrene copolymers containing 8.58 percent of bound-styrene were investigated by means of an adiabatic calorimeter from $16^{\circ}$ to $330^{\circ} \mathrm{K}$. The $41^{\circ} \mathrm{F}$ copolymer was found to crystallize in the temperature range from $210^{\circ}$ to $285^{\circ} \mathrm{K}$. The $122^{\circ} \mathrm{F}$ copolymer did not exhibit any crystallization. The glasstransformation temperatures of the $41^{\circ}$ and $122^{\circ} \mathrm{F}$ copolymers were $200^{\circ}$ and $193^{\circ} \mathrm{K}$, respectively. The effects of heat treatment upon the heat capacity and the glass-transformation temperature have been studied. The results of the heat-capacity measurements were used to compute heat capacity, enthalpy, and entropy from $0^{\circ}$ to $33 \Omega^{\circ} \mathrm{K}$ at 5 -deg intervals.
\end{abstract}

\section{Introduction}

The literature is copious with studies involving the physical and chemical properties of various rubber polymers prepared from different recipes. These investigations have principally in mind the correlation of the observed properties with the structure of the polymers - the structure or the composition being determined by chemical methods, derived judiciously from the units that compose the polymers, or deduced from the various observed properties themselves. The situation is complicated by many variables in the recipes, such as polymerization temperature, percentage conversion, catalyst, modifier, and others, both controllable and noncontrollable, which affect the internal structure of the final product. For example, in the polymerization of dienes many of the above factors influence the degree of $1-4,1-2$, cis, or trans addition as well as cross-linking. Furthermore, in many instances the noncontrolled variables outweigh the controlled variables in determining the physical property.

Some of the physical properties of rubber polymers have been known to be dependent to a certain extent upon their previous thermal and mechanical history. For example, in the heat-capacity measurements with Hycar O. R.-15 [1] ${ }^{2}$ and GR-S [2], the direction of the temperature drift in the temperature range of glass transformation is shown to depend upon the rate at which the polymers were cooled prior to the measurements. The temperature drift observed can be explained in terms of the long relaxation times encountered for certain degrees of freedom in the polymeric substance to reach equilibrium. At the lower temperatures a given degree of freedom can be essentially frozen-in, and at the higher temperatures the attainment of equilibrium for that degree of freedom can be very rapid. The temperature drift is observed in the intermediate temperature range when the relaxation time for the degree of freedom is of the same order of magnitude as the time for the heat-capacity measurements. In the temperature

${ }_{1}^{1}$ This paper-is based on the work sponsored by the Reconstruction Finance Corp., Synthetic Rubber Dirision.

${ }_{2}$ Figures in brackets indicate the literature references at the end of this paper. range of glass transformation the relaxation time for certain degrees of freedom in polymers comes within this magnitude. Similarly, as is pointed out later, the crystallization and melting processes in polymers have a relaxation time within this range. Thus, when the polymer is cooled rapidly through the glasstransformation interval (or through the crystallization interval) a certain portion of the polymer molecules fails to undergo transition from the higher- to the lower-energy states. During the heat-capacity experiments and when heating to temperatures near the glass-transformation interval, the frozen-in degrees of freedom become gradually excited and transitions occur within the polymer in the direction of equilibrium. In this case, the polymer molecules transform into the lower-energy states with the consequent liberation of energy and upward temperature drift. On the other hand, when the polymer is cooled slowly through the glass-transformation interval, more polymer molecules have a chance to transform into the lower-energy states. Upon heating to the glass-transformation range, the polymer molecules transform into the higher-energy states accompanied by an absorption of energy and a downward temperature drift.

The glass transformation, which is associated with many polymers, supercooled liquids, and other noncrystalline solids, arises from the freezing-in or the increasing length of relaxation time for certain degrees of freedom and is characterized in calorimetry by a steep decrease in the heat capacity with decrease in temperature. The thermal coefficient of expansion decreases rapidly in a similar manner, and there are many other physical properties that are aftected similarly within the same temperature range. The glass transformation is not as sharp as first-order transitions, but is spread over a 5- to 10-deg interval. As the relaxation time for equilibrium in this temperature range is of the same order of magnitude as the experimental measurements, the heat-capacity values obtained are dependent upon the rate of cooling through this interval as well as the time awaited for temperature measurements. Consequently, the heatcapacity values are somewhat scattered.

Natural rubber and other natural and synthetic 
polymers are known to crystallize over a wide range of temperature. There is only a short-range order within any crystalline polymeric substance and along a single polymer molecule both crystalline and amorphous structures exist simultaneously. Recent Xray studies [3] have shown that the crystallinity in natural rubber increased with storage, and that even after 30 years of storage the crystallization process had not reached the state of equilibrium. The crystallization and melting processes of polymers are observed as temperature drifts in calorimetry. The lower temperature limit of this crystallization range is set by the lack of thermal motion to attain crystal configuration; and beyond the upper limit, the thermal motion is sufficient to make the time spent in a crystalline state short and the polymer is amorphous. Thus, the degree of crystallinity of the polymer at temperatures below the crystallization range, is determined to a certain extent by the rate of cooling through this range.

This report deals with the heat-capacity investigation of two butadiene-styrene copolymers containing 8.58 percent of bound-styrene and prepared at $41^{\circ} \mathrm{F}\left(5^{\circ} \mathrm{C}\right)$ and $122^{\circ} \mathrm{F}\left(50^{\circ} \mathrm{C}\right)$. These two materials were investigated to determine the effect of the polymerization temperature upon their relative crystallizability, glass-transformation temperature, and heat capacity. The effects of heat treatment upon the heat capacity and the glass-transformation temperature have been studied, and the results of the measurements were used to compute heat capacity, enthalpy, and entropy of the polymers at 5-deg intervals from $0^{\circ}$ to $330^{\circ} \mathrm{K}$.

The calorimetric method, as applied in this investigation, is sensitive to changes in the polymer in which thermal energy as little as 0.03 abs $\mathrm{j} \mathrm{min}^{-1}$ is evolved or absorbed. This method was used to detect temperatures at which thermal effects occurred and at which transitions took place. The temperature range of crystallization in the $41^{\circ} \mathrm{F}$ copolymer and the glass-transformation temperature of both copolymers were determined.

\section{Apparatus and Method}

The details of the calorimetric apparatus and method used in this investigation can be found in the previous reports dealing with 1,3-butadiene [4] and diphenyl ether [5]. A small quantity of helium gas, sealed in with each polymer sample, supplemented the vanes in enhancing the attainment of thermal equilibrium. The temperature measurements were based on the platinum resistance thermometer calibrated at this Bureau in accordance with the 1948 International Temperature Scale [6] and between $10^{\circ}$ and $90^{\circ} \mathrm{K}$ on a provisional scale [7], consisting of a set of platinum resistance thermometers calibrated against a helium gas thermometer. The temperatures expressed in degrees Kelvin were obtained by adding $273.16^{\circ}$ to the observed temperatures in degrees Celsius.

In order to study in what way the heat treatment affects the heat-capacity results, two series of experi- ments were carried out in the temperature range from $80^{\circ}$ to $280^{\circ} \mathrm{K}$. In one series, the polymer was shock-cooled by immersing the calorimeter in liquid nitrogen with helium gas in the space surrounding the sample container. By means of this procedure, the sample was cooled from room temperature to about $90^{\circ} \mathrm{K}$ in $30 \mathrm{~min}$ and to about $80^{\circ} \mathrm{K}$ in an additional $30 \mathrm{~min}$. In the second series of measurements, the polymer was cooled slowly by maintaining a high vacuum around the sample container. The cooling process was prolonged by successively using dry ice and then liquid nitrogen. In several cases the $41^{\circ} \mathrm{F}$ polymer was left between $200^{\circ}$ and $230^{\circ} \mathrm{K}$ for a number of days to increase the crystallinity by allowing a longer time for crystallization. After cooling the polymer to the desired temperature, the heat-capacity measurements were made at progressively higher temperatures, the final temperature of the first measurement being the initial temperature of the second measurement, and so forth up the temperature scale. As heat-capacity measurements with simpler substances [5, 8] show that normal temperature equilibrium was established in 6 to $7 \mathrm{~min}$ after the heating period, any persistent temperature drift after the eighth minute was considered to arise from the thermal effects in the polymeric material.

The net heat capacity, or the heat capacity of the polymer, was obtained by subtracting the heat capacity of the empty container from the gross heat capacity. At the lower temperatures at which the slope of the heat-capacity curve changes rapidly, the temperature increase per heating period was made as low as 2 to $3 \mathrm{deg}$ to make insignificant the curvature correction to the experimental heat capacity. As the curvature does not change rapidly at the higher temperatures, larger temperature intervals of 7 to $9 \mathrm{deg}$ were used. The heat capacities tabulated at 5-deg intervals in tables 4 and 7 were obtained by graphical smoothing of the net heat capacities. The heat capacities in the transition regions were obtained by methods later described.

\section{Samples}

The two 90/10 butadiene-styrene copolymers investigated were obtained from different sources. The history of the rubber polymer, designated X-454 and obtained through the Copolymer Corp., Baton Rouge, La., is not completely known. This copolymer was emulsion polymerized at $41^{\circ} \mathrm{F}\left(5^{\circ} \mathrm{C}\right)$ with the initial butadiene-styrene charge ratio at $90 / 10$; the emulsifier was Dresinate 731 and the modifier was probably Sulfole B-8. The reaction was "shortstopped" at about 55-percent conversion, using ditertiary butylhydroquinone. No further information is known about this copolymer. The GL-658 copolymer prepared at $122^{\circ} \mathrm{F}\left(50^{\circ} \mathrm{C}\right)$ was obtained through the University of Akron-Government Laboratories [9], and the details concerning this material are found in the reference given. The copolymer was emulsion polymerized with the same initial butadiene-styrene charge ratio as the $41^{\circ} \mathrm{F}$ copoly- 
mer, using, however, as emulsifier soap flakes (SF), and as modifying agent normal-dodecyl mercaptan (DDM). The polymerization reaction was activated by potassium persulfate and "short-stopped" at about 72-percent conversion by means of hydroquinone.

The polymers were purified by M. Tryon of the Rubber Section of the National Bureau of Standards, and the purification procedure was as follows. The material was first dissolved in benzene and centrifuged to eliminate solid particles. This solution was added dropwise into well-stirred methyl alcohol to coagulate the polymer. The coagulated polymer was then redissolved in benzene. The solution and subsequent precipitation processes were carried out three times. This procedure eliminated fatty acids and their salts, stabilizer (phenylbetanaphthylamine), and some low-molecular-weight polymers. After dissolving the polymer for the fourth time, about 0.1 percent of phenylbetanaphthylamine was added to the benzene solution as a stabilizer. Subsequently, the benzene was removed by pumping on the frozen polymer solution held at the dry-ice temperature, leaving the stabilizer behind with the polymer. This process yielded a spongy mass, which was pressed into $1 / 4$-inch sheets. The polymer samples were received from the Rubber Section in this form, and they were cut to size to fit between the vanes of the sample container. The samples were pumped at high vacuum for 3 days at $25^{\circ} \mathrm{C}$ and 1 day at $50^{\circ} \mathrm{C}$ to eliminate volatile impurities such as moisture, air, and benzene. Following this, the container was sealed with a small quantity of helium gas. The mass of the $\mathrm{X}-454$ copolymer investigated was $41.336 \mathrm{~g}$, and that of the GL- 658 was $40.349 \mathrm{~g}$.

A portion of the purified polymers was analyzed for composition. The results are given in table $1 .^{3}$ The styrene contents given in the table were computed from the carbon-hydrogen ratios corrected for the mercaptan content. The phenylbetanaphthylamine was added after the analysis.

TABLE 1. Composition of the copolymers

\begin{tabular}{|c|c|c|}
\hline & \multicolumn{2}{|c|}{ Percentage by weight } \\
\hline & $\mathrm{X}-454$ & GL -658 \\
\hline $\begin{array}{l}\text { Carbon } \\
\text { Hydrogen } \\
\text { Sulfur } \\
\text { Oxygen } \\
\text { Ash }\end{array}$ & $\begin{array}{c}88.869 \\
10.872 \\
.056 \\
.235 \\
.18\end{array}$ & $\begin{array}{c}88.907 \\
10.8982 \\
.136 \\
.16 \\
.104\end{array}$ \\
\hline Styrene. & 8.58 & 8. 58 \\
\hline Phenylbetanaphthylamine. & .1 & .1 \\
\hline
\end{tabular}

\section{Results}

\subsection{X-454, $41^{\circ} \mathrm{F}$ Copolymer}

The experimental details regarding heat treatments, temperature range of the measurements, and temperature drifts with the $\mathrm{X}-454$ copolymer are

\footnotetext{
3 The analyses were made by R. A. Paulson and M. Tryon of the Bureau.
}

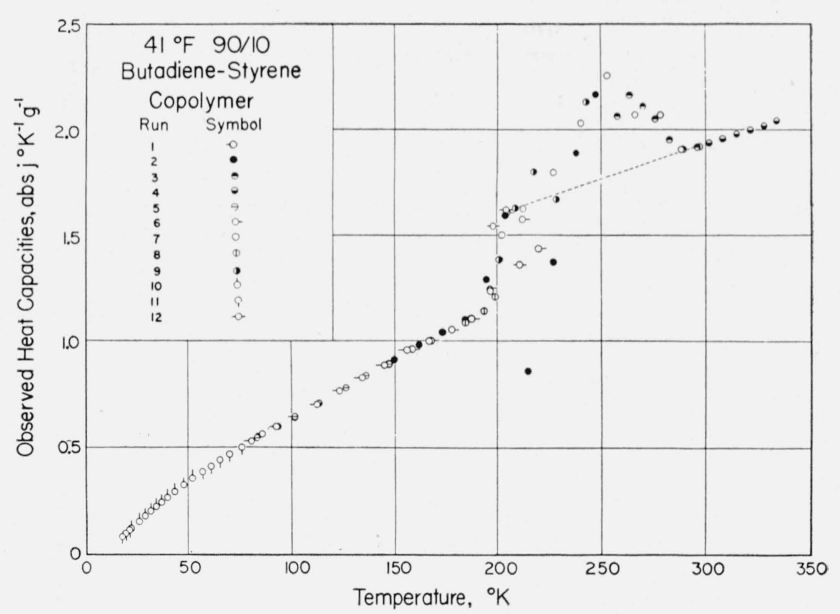

Figure 1. Observed heat capacities of the $X-454,41^{\circ} \mathrm{F}$ butadiene $(90)$ _-styrene $(10)$ copolymer.

The broken line was obtained by extrapolating the heat capacities in the amorphous range.

summarized in table 2. The observed heat-capacity values are given in table 3 and plotted in figure 1 . The heat-capacity measurements in runs 1,2 , and 3 were made after shock-cooling the polymer from room temperature to that of liquid nitrogen. In these experiments the upward temperature drifts, observed in the range of temperature from about $170^{\circ}$ to $280^{\circ}$ $K$, are attributed to slow changes in the polymer to lower states of energy. In run 2 the upward temperature drift at $220^{\circ} \mathrm{K}$ was a much as 0.09 deg per min 40 min after the end of the heating period. As shown in figure 1, the heat-capacity results in run 2 (indicated by filled-in circles) rise steeply over the temperature interval from about $195^{\circ}$ to $205^{\circ} \mathrm{K}$. Then, there follows a sudden drop and again a rise in the heat capacity. The heatcapacity rise in the interval $195^{\circ}$ to $205^{\circ} \mathrm{K}$ is attributed to glass transformation. The glasstransformation temperature is taken to be $200^{\circ} \mathrm{K}$. The sudden decrease that follows is caused by the crystallization of the polymer, for apparent heat capacity falls off with crystallization. The rise following this is from the melting of the polymer crystallites. The results (fig. 1) of all heat-capacity measurements are relatively high in the temperature interval $230^{\circ}$ to $280^{\circ} \mathrm{K}$, and during the heatcapacity measurements upward temperature drifts were observed in this range. It is believed that irreversible melting took place in the vicinity of the heater (central well) because during the heating process the temperature is invariably higher near the heater. For this reason the heating rate, or the power, somewhat affects the heat capacity. During the equilibrating period some of the melted crystallites recrystallize, and also new crystallites form with the increased thermal energy now available for orientation. The apparent high heat capacity is indicative of a relatively larger amount of melting in the particular heating interval in comparison to crystallization. Thus the amount of the polymer melted is greater than the amount crystallized in the temperature range $230^{\circ}$ to $280^{\circ} \mathrm{K}$, 
TABLE 2. Heat treatments and observations with the $41^{\circ} \mathrm{F}$ butadiene (90)-styrene (10) copolymer $X-454$

(Temperatures are in ${ }^{\circ} \mathrm{K}$ )

\begin{tabular}{|c|c|c|c|}
\hline Run & Treatment of sample & $\begin{array}{l}\text { Temperature } \\
\text { range of } \\
\text { measurements }\end{array}$ & Drift observation \\
\hline 1 & $\begin{array}{l}\text { Cooled rapidly from } \\
\text { room temperature to } \\
77^{\circ} \text {. }\end{array}$ & $77^{\circ}$ to $171^{\circ}$ & Upward drift at $171^{\circ}$. \\
\hline 2 & $\begin{array}{l}\text { Cooled rapidly from } \\
\text { room temperature to } \\
78^{\circ} \text { and heated to } 143^{\circ} \text {. }\end{array}$ & $143^{\circ}$ to $251^{\circ}$ & $\begin{array}{l}\text { Upward drift from } \\
178^{\circ} \text { to } 251^{\circ} \text {. }\end{array}$ \\
\hline 3 & $\begin{array}{l}\text { Cooled rapidly from } \\
\text { room temperature to } \\
251^{\circ}\end{array}$ & $251^{\circ}$ to $298^{\circ}$ & $\begin{array}{l}\text { Upward drift from } \\
251^{\circ} \text { to } 278^{\circ} \text {. }\end{array}$ \\
\hline 4 & $\begin{array}{l}\text { Left at room tempera- } \\
\text { ture overnight. }\end{array}$ & $298^{\circ}$ to $337^{\circ}$. & No drift. \\
\hline 5 & $\begin{array}{l}\text { Cooled slowly from room } \\
\text { temperature to } 200^{\circ} \\
\text { and left between } 200^{\circ} \\
\text { and } 230^{\circ} \text { for } 3 \text { days and } \\
\text { cooled to } 78^{\circ} \text {. }\end{array}$ & $78^{\circ}$ to $151^{\circ}$ & $\begin{array}{l}\text { Downward drift from } \\
131^{\circ} \text { to } 151^{\circ} \text {. }\end{array}$ \\
\hline 6 & $\begin{array}{l}\text { A llowed to remain } \\
\text { around } 150^{\circ} \text { overnight } \\
\text { and heated to } 153^{\circ} \text {. }\end{array}$ & $153^{\circ}$ to $223^{\circ}$ & $\begin{array}{l}\text { Downward drift from } \\
153^{\circ} \text { to } 172^{\circ} \text {; up- } \\
\text { ward from } 191^{\circ} \text { to } \\
223^{\circ} \text {. }\end{array}$ \\
\hline 7 & $\begin{array}{l}\text { Cooled to } 193^{\circ} \text { overnight } \\
\text { with dry ice. }\end{array}$ & $193^{\circ}$ to $300^{\circ}$ & $\begin{array}{l}\text { Downiw ard drift from } \\
193^{\circ} \text { to } 199^{\circ} ; \text { up- } \\
\text { ward from } 204^{\circ} \text { to } \\
273^{\circ} \text {. }\end{array}$ \\
\hline 8 & $\begin{array}{l}\text { Cooled slowly to } 200^{\circ} \text {, } \\
\text { allowed to remain be- } \\
\text { tween } 200^{\circ} \text { and } 230^{\circ} \\
\text { for } 1 \text { week, and cooled } \\
\text { rapidly to } 171^{\circ} \text {. }\end{array}$ & $171^{\circ}$ to $200^{\circ}$ & $\begin{array}{l}\text { Upward drift from } \\
188^{\circ} \text { to } 200^{\circ} \text {. }\end{array}$ \\
\hline 9 & $\begin{array}{l}\text { Allowed to remain at } \\
\text { dry ice temperature } \\
\text { overnight. }\end{array}$ & $\begin{array}{l}196^{\circ} \text { to } 295^{\circ} ; 251^{\circ} \\
\text { to } 295^{\circ} \text { was } \\
\text { one heat. }\end{array}$ & $\begin{array}{l}\text { Downward drift at } \\
211^{\circ} \text {; upward drift } \\
\text { from } 222^{\circ} \text { to } 251^{\circ} \text {. }\end{array}$ \\
\hline 10 & $\begin{array}{l}\text { Allowed to remain at } \\
\text { dry ice temperature } \\
\text { for } 1 \text { week and cooled } \\
\text { to liquid } \mathrm{H}_{2} \text { tempera- } \\
\text { ture. }\end{array}$ & $20^{\circ}$ to $53^{\circ} \ldots$ & No drift. \\
\hline 11 & Continuation of run 10 & $\begin{array}{l}16^{\circ} \text { to } 22^{\circ} \text { and } \\
51^{\circ} \text { to } 78^{\circ} \text {. }\end{array}$ & Do. \\
\hline 12 & $\begin{array}{l}\text { Cooled slowly to } 200^{\circ} \\
\text { and allowed to remain } \\
\text { between } 200^{\circ} \text { and } 230^{\circ} \\
\text { for } 3 \text { weeks. }\end{array}$ & $194^{\circ}$ to $213^{\circ}$ & $\begin{array}{l}\text { Upward drift from } \\
206^{\circ} \text { to } 213^{\circ} \text {. }\end{array}$ \\
\hline
\end{tabular}

TABLE 3. Observed heat capacities of $41^{\circ} F$ butadiene (90)styrene (10) copolymer $X-454$

\begin{tabular}{|c|c|c|c|c|c|c|c|c|}
\hline Run & $T$ & $C$ & Run & $T$ & $C$ & Run & $T$ & $C$ \\
\hline 3 & $\begin{array}{c}{ }^{\circ} K \\
79.91 \\
85.21 \\
91.68 \\
100.76 \\
111.49 \\
122.30 \\
133.59 \\
144.23 \\
155.00 \\
165.97 \\
148.86 \\
160.87 \\
172.34 \\
183.34 \\
193.65 \\
202.91 \\
213.69 \\
226.10 \\
237.00 \\
246.42 \\
256.69 \\
262.95 \\
269.15 \\
275.44 \\
281.87 \\
288.45 \\
295.05 \\
301.05 \\
307.56 \\
314.28 \\
320.94 \\
327.28 \\
333.58\end{array}$ & $\begin{array}{c}a b s j \\
{ }^{\circ} K^{-1} g^{-1} \\
0.5362 \\
.5671 \\
.6016 \\
.6497 \\
.7089 \\
.7704 \\
.8330 \\
.8923 \\
.9622 \\
1.005 \\
0.9183 \\
.9850 \\
1.047 \\
1.106 \\
1.294 \\
1.597 \\
0.8616 \\
1.376 \\
1.894 \\
2.171 \\
2.068 \\
2.167 \\
2.114 \\
2.058 \\
1.957 \\
1.911 \\
1.923 \\
1.940 \\
1.961 \\
1.982 \\
2.001 \\
2.020 \\
2.041\end{array}$ & 8 & $\begin{array}{r}{ }^{\circ} K \\
82.57 \\
91.92 \\
100.51 \\
112.50 \\
125.78 \\
136.32 \\
146.32 \\
157.49 \\
166.89 \\
176.80 \\
186.36 \\
195.47 \\
203.63 \\
211.22 \\
219.02 \\
195.70 \\
201.31 \\
211.48 \\
226.02 \\
239.49 \\
252.05 \\
265.46 \\
277.61 \\
287.55 \\
296.43 \\
183.68 \\
192.47 \\
198.19 \\
200.27 \\
207.66 \\
216.57 \\
227.60 \\
242.04\end{array}$ & $\begin{array}{c}a b s j \\
{ }^{-1} K^{-1} g^{-1} \\
0.5491 \\
.6006 \\
.6458 \\
.7101 \\
.7831 \\
.8408 \\
.8955 \\
.9561 \\
1.006 \\
1.057 \\
1.108 \\
1.248 \\
1.608 \\
1.580 \\
1.442 \\
1.240 \\
1.507 \\
1.630 \\
1.802 \\
2.033 \\
2.257 \\
2.077 \\
2.072 \\
1.912 \\
1.926 \\
1.090 \\
1.143 \\
1.212 \\
1.389 \\
1.630 \\
1.803 \\
1.672 \\
2.133\end{array}$ & 12 & $\begin{array}{c}{ }^{\circ} K \\
21.73 \\
25.49 \\
28.43 \\
31.13 \\
33.71 \\
36.39 \\
39.17 \\
42.77 \\
47.03 \\
51.04 \\
17.34 \\
19.01 \\
21.04 \\
56.25 \\
60.28 \\
64.73 \\
69.47 \\
75.10 \\
197.23 \\
203.43 \\
209.81\end{array}$ & $\begin{array}{c}a b s j \\
{ }^{\circ} K^{-1} g^{-1} \\
0.1223 \\
.1560 \\
.1813 \\
.2046 \\
.2261 \\
.2477 \\
.2695 \\
.2967 \\
.3280 \\
.3592 \\
.0847 \\
.0989 \\
.1163 \\
.3910 \\
.4160 \\
.4462 \\
.4721 \\
.5036 \\
1.548 \\
1.622 \\
1.367\end{array}$ \\
\hline
\end{tabular}

although the observed upward temperature drifts indicate crystallization to be taking place. On the other hand, in run 2 , as pointed out earlier, the low heat capacity just above the glass-transformation temperature arises from a large amount of crystallization. As temperatures used in heat-capacity calculations were determined during temperature drifts, the heat-capacity values are different from the values that would be obtained if thermal equilibrium had been reached. The temperature equilibrium, however, was awaited sufficiently long so that the general nature of each heat-capacity value is preserved.

The heat-capacity curve (fig. 1) is smooth in the range of temperature in which run 4 was made. The polymer is considered to be completely amorphous above $285^{\circ} \mathrm{K}$.

The remainder of the experiments were made after cooling the polymer slowly to obtain a well-crystallized and annealed sample. The results of the measurements in runs 5,6 , and 7 , which were made on successive days, showed that, in general, after annealing the polymer, the heat-capacity values between $210^{\circ}$ and $285^{\circ} \mathrm{K}$ became higher (see tables 2 , and 3 , and fig. 1). This indicates that the amount of crystallization that took place during these heatcapacity measurements was lower than in the measurements when the polymer was shock-cooled. In these experiments, the downward temperature drifts below $200^{\circ} \mathrm{K}$ are considered to arise from the slow transition of the polymer molecules from lowerto higher-energy states, these states being associated in some way with glass transformation. The downward temperature drifts above this temperature are attributed to slow melting of the crystallites. As relatively low heat-capacity results were obtained in the temperature interval $200^{\circ}$ to $230^{\circ} \mathrm{K}$, the polymer was held within this temperature interval for 1 week to increase the degree of erystallinity. Runs 8 and 9 , carried out on successive days, are experiments with the material so treated. The heat-capacity results in these measurements were not as low as found in runs 2 and 6 ; however, a relatively low value was obtained at $227.60^{\circ} \mathrm{K}$. The experiments in run 12 were made to determine whether a longer conditioning period would eliminate completely the low heat-capacity values. In spite of the 3-weeks' conditioning, the experiments of run 12 yielded low values. In this run, the polymer was probably not as well crystallized as expected. The interpretation of the observed results with this polymer is made difficult by the closeness of the crystallization to the glass-transformation temperature. In the crystallization interval, probably the melting and crystallization processes occur simultaneously. The direction of the temperature drift is an indication of the predominating process at the time of the measurement. Also, the direction of the drift is dependent, as in the glass-transformation temperature range, upon the previous heat treatment, the rate at which the new condition was reached from the former, and the time lapse between the attainment of the new condition and the experimental observation. 
The annealing process, which increased the crystallinity in the polymer, yielded lower heat-capacity values in the temperature range below $200^{\circ} \mathrm{K}$. The difference between the results of the shock-cooled and annealed polymer is about 1 percent at $185^{\circ} \mathrm{K}$ and about 0.5 percent at $80^{\circ} \mathrm{K}$. The heat-capacity values given in table 4 were calculated from the results of the annealed polymer. The values at $15^{\circ} \mathrm{K}$ and below were obtained by extrapolation, using the Debye function,

$$
C=0.2489 D\left(\frac{90.54}{T}\right),
$$

which was fitted to experimental values between $17^{\circ}$ and $25^{\circ} \mathrm{K}$. The heat-capacity values in the range $190^{\circ}$ to $295^{\circ} \mathrm{K}$ were estimated from a heat-capacitytemperature curve, in which the values in the crystallization range were taken along the broken curve (hypothetical heat-capacity curve for amorphous copolymer), as shown in figure 1 . The estimated values are given in table 4 . The broken curve was obtained by linear extrapolation of the experimental values in the temperature range $290^{\circ}$ to $330^{\circ} \mathrm{K}$. Above the glass-transformation temperature, the heat-capacity curves for Hycar 0.R. -15 [1] and GR$\mathrm{S}[2]$ were found to be closely linear. The results with the GL-658 copolymer, which was found to give no crystallization, are also closely linear between $250^{\circ}$ and $330^{\circ} \mathrm{K}$; extrapolation below $250^{\circ}$ to the glasstransformation temperature, however, would result in a deviation of 4 percent at $200^{\circ} \mathrm{K}$.

TABLE 4. Heat capacity, enthalpy, and entropy of $41^{\circ} F$ butadiene (90)-styrene (10) copolymer $X-454$

\begin{tabular}{|c|c|c|c|c|c|c|c|}
\hline$T$ & $C$ & $\left(H_{T}-H_{0}\right)$ & $\left(S_{T}-S_{0}\right)$ & $T$ & $C$ & $\left(H_{T}-H_{0}\right)$ & $\left(S_{T}-S_{0}\right)$ \\
\hline${ }^{\circ} K$ & $a b s j^{\circ} K^{-1}$ & $a b s j g^{-1}$ & $a b s j^{\circ} K^{-1}$ & ${ }^{\circ} K$ & $a b s j^{\circ} K^{-1}$ & $a b s j g^{-1}$ & $a b s j^{\circ} K^{-1}$ \\
\hline 0 & & & & 175 & 1. 048 & $96.36^{\circ}$ & 1. 048 \\
\hline 5 & 0.0033 & 0.0041 & 0.0011 & 180 & 1. 074 & 101.7 & 1. 078 \\
\hline 10 & .0248 & .0641 & .0086 & $18 b$ & 1. 101 & 107. 1 & 1.107 \\
\hline 15 & .0653 & .2855 & .0260 & 190 & 1. 130 & 112.7 & 1. 137 \\
\hline 20 & .1074 & .7164 & .0505 & 195 & 1. 18 & $\ldots$ & -...... \\
\hline 25 & .1519 & 1. 364 & .0793 & 200 & 1. 56 & & \\
\hline 30 & .1949 & 2. 232 & .1108 & 205 & 1. 61 & & \\
\hline 35 & .2365 & 3.311 & .1440 & 210 & 1. 63 & & \\
\hline 40 & .2758 & 4. 593 & .1781 & 215 & 1. 65 & -....... & -...... \\
\hline 45 & .3133 & 6.066 & .2128 & 220 & 1.67 & -....... & ......... \\
\hline 50 & .3508 & 7. 727 & .2478 & 225 & 1. 68 & & \\
\hline 55 & .3840 & 9.565 & .2828 & 230 & 1.70 & ... & \\
\hline 60 & .4143 & 11. 56 & .3175 & 235 & 1. 72 & - & -..... \\
\hline 65 & .4448 & 13. 71 & .3519 & 240 & 1. 74 & .......... & -........ \\
\hline 70 & .4750 & 16.01 & .3859 & 245 & 1.75 & - & -....... \\
\hline 75 & .5050 & 18. 46 & .4197 & 250 & 1. 77 & & \\
\hline 80 & .5345 & 21.06 & .4533 & 255 & 1. 79 & $\ldots$ & $\ldots$ \\
\hline 85 & .5639 & 23.80 & .4866 & 260 & 1.80 & -... &.- \\
\hline 90 & .5906 & 26.69 & .5196 & $26 \mathrm{~s}$ & 1.82 & $\ldots$. & - \\
\hline 95 & .6168 & 29.71 & .5522 & 270 & 1.84 & ...... & -...... \\
\hline 100 & .6432 & 32.86 & .5845 & 275 & 1.85 & & \\
\hline 105 & .6698 & 36.14 & .6165 & 280 & 1.87 & $\ldots$ & $\ldots$ \\
\hline 110 & .6963 & 39.56 & .6483 & 285 & 1.89 & $\ldots \ldots$ & - \\
\hline 115 & .7234 & 43.11 & .6798 & 290 & 1. 90 & & \\
\hline 120 & .7510 & 46.79 & .7112 & 295 & 1.923 & 309.1 & 1. 947 \\
\hline 125 & .7788 & 50.62 & .7424 & 298.16 & 1.931 & 315.2 & 1. 968 \\
\hline 130 & .8063 & 54.58 & .7735 & 300 & 1. 937 & 318.8 & 1. 979 \\
\hline 135 & .8337 & 58.68 & .8045 & 305 & 1. 952 & 328.5 & 2. 012 \\
\hline 140 & .8610 & 62.92 & .8353 & 310 & 1. 968 & 338.3 & 2. 044 \\
\hline 145 & .8883 & 67.29 & .8660 & 315 & 1.983 & 348.2 & 2. 075 \\
\hline 150 & .9156 & 71.80 & .8965 & 320 & 1.997 & 358.1 & 2. 106 \\
\hline 155 & .9428 & 76.45 & .9270 & 325 & 2. 012 & 368. 2 & 2. 138 \\
\hline 160 & .9696 & 81. 23 & .9574 & 330 & 2. 028 & 378.3 & 2. 168 \\
\hline 165 & .9958 & 86.14 & 9876 & & & & \\
\hline 170 & 1. 022 & 91.18 & 1.018 & & & & \\
\hline
\end{tabular}

The enthalpy values given in table 4 , except in the range $190^{\circ}$ to $295^{\circ} \mathrm{K}$, were obtained by evaluating the expression

$$
H_{T}-H_{0}=\int_{0}^{T} C d T .
$$

$\mathrm{H}_{0}$ is the enthalpy at absolute zero of temperature. The enthalpy change over the temperature interval $190^{\circ}$ to $295^{\circ} \mathrm{K}$ was computed from the experimental heat-capacities obtained in run 7 by summing the product of individual net heat capacities and the corresponding temperature rise. At other temperatures, except below $15^{\circ} \mathrm{K}$, the expression in eq (1) was evaluated by numerical integration, using fourpoint Lagrangian integration coefficients [11]. Below $15^{\circ} \mathrm{K}$, the enthalpy was evaluated by using the Debye function given above.

As previously stated, in the crystallization interval the hypothetical amorphous copolymer would probably follow the broken heat-capacity curve. By integrating along this curve (see fig. 1 and table 4) the change in enthalpy of the "amorphous" copolymer between $190^{\circ}$ and $295^{\circ} \mathrm{K}$ was found to be about 180 abs $\mathrm{j} \mathrm{g}^{-1}$. Comparing this value with the 196.46 and 198.97 abs $\mathrm{j} \mathrm{g}^{-1}$ obtained in runs 7 and 9, respectively, for the same temperature interval, the heat of fusion per gram would be about 16 to 19 abs $\mathrm{j}$. The range of these values is close to 16.71 abs $\mathrm{j} \mathrm{g}^{-1}$ obtained by Bekkedahl and Matheson [10] with natural rubber. As shown by the difference in the values obtained in runs 7 and 9 , these values are dependent upon the heat treatment. As the copolymer was annealed for a longer period prior to run 9 than run 7 , the larger value in run 9 seems consistent.

Entropy values given in table 4 were obtained in a similar manner as were enthalpies by evaluating the thermodynamic expression:

$$
S_{T}-S_{0}=\int_{0}^{T} \frac{C d T}{T}
$$

$S_{0}$ is the entropy at absolute zero of temperature. Between $190^{\circ}$ and $295^{\circ} \mathrm{K}$, the entropy change was computed using the experimental data obtained in run 7 by summing the individual $C \Delta T / T$ values. $C$ is the net heat capacity, and $\Delta T$ and $T$ are the corresponding temperature increase and midtemperature, respectively.

The enthalpy and entropy values given in table 4 were evaluated from the results of the experiments with the annealed polymer. No attempt was made to make a similar table of the results of shockcooled experiments.

\subsection{GL-658, $122^{\circ}$ F Copolymer}

The heat treatments and the subsequent heatcapacity experiments with the GL-658 copolymer were carried out in a similar manner as with the $\mathrm{X}-454$ copolymer. The details regarding the heat treatments, temperature range of the measurements, and the drift observations with this copolymer are 


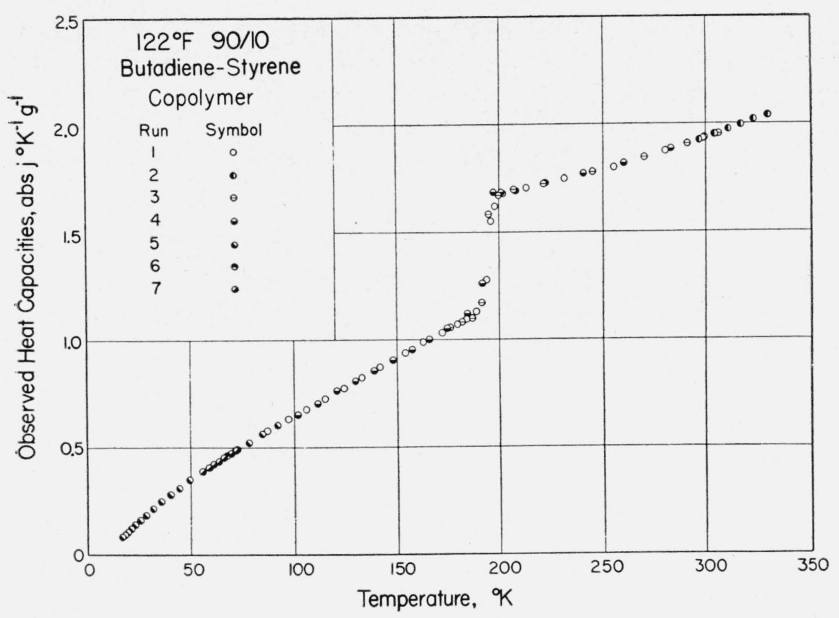

Figure 2. Observed heat capacities of the GL-658, 122 ${ }^{\circ} \mathrm{F}$ butadiene (90)-styrene (10) copolymer.

summarized in table 5. The observed heat-capacity values are given in table 6 and plotted in figure 2 . The experiments in runs 1 and 3 were made after rapidly cooling the copolymer. In these measurements upward temperature drifts were observed in the temperature range from about $167^{\circ}$ to $195^{\circ} \mathrm{K}$ and no drift above $195^{\circ} \mathrm{K}$. The results of runs 1,2 , and 3 show that the glass transformation occurs at about $190^{\circ}$ to $195^{\circ} \mathrm{K}$ and that crystallization does not occur in this copolymer. The heat-capacity results (run 4), obtained after cooling the copolymer slowly, showed downward temperature drifts from $189^{\circ}$ to $195^{\circ} \mathrm{K}$ and no drift above $195^{\circ} \mathrm{K}$. The downward drift in temperature is considered to arise from slow changes in the polymer to higher states of energy. In these experiments the heat-capacity curve at the glass-transformation interval rises a few degrees sooner than the curve obtained when the copolymer was rapidly cooled. The glass-transformation temperature is taken to be $193^{\circ} \mathrm{K}$, the temperature at the midpoint of the upward sweep in the curve. Between $90^{\circ}$ and $165^{\circ} \mathrm{K}$, the heats capacity results seem essentially the same, regardlesof the heat treatment. The maximum spread in the over-all heat-capacity results is \pm 0.2 percent at the higher temperatures (above $195^{\circ} \mathrm{K}$ ). From $165^{\circ} \mathrm{K}$ to the glass-transformation temperature the results show greater scattering, as much as 1 percent. The heat-capacity values show no clear correlation with heat treatment because of the obscuring effect the temperature drifts have on the heat capacity. At $177^{\circ} \mathrm{K}$ the temperature was drifting upward after 30 min. Thus, no further attempt was made in other experiments to reach thermal equilibrium. The temperature measurements were started at times (about 6 to 7 min after the end of heating) usually required for thermal equilibrium with simpler materials $[5,8]$. Experience with the $\mathrm{X}-454$ copolymer and the other polymers, recently investigated at the Bureau, shows that the waiting period for thermal equilibrium can be extremely long. The heat-capacity results (runs 5, 6, and 7) below $90^{\circ} \mathrm{K}$ do not show any unusual effects.
TABLE 5. Heat treatment and observations with the $122^{\circ} \mathrm{F}$ butadiene (90)-styrene (10) copolymer GL-658

( Temperatures are in ${ }^{\circ} \mathrm{K}$ )

\begin{tabular}{|c|c|c|c|}
\hline Run & Treatment of sample & $\begin{array}{l}\text { Temper- } \\
\text { ature range } \\
\text { of measure- } \\
\text { ments }\end{array}$ & Drift observations \\
\hline 1 & $\begin{array}{l}\text { Cooled rapidly from room } \\
\text { temperature to } 77^{\circ} \text {. }\end{array}$ & $81^{\circ}$ to $307^{\circ}$ & $\begin{array}{l}\text { Upward drift from } 167^{\circ} \\
\text { to } 195^{\circ} \text { No drift }\end{array}$ \\
\hline 2 & $\begin{array}{l}\text { Left at room temperature } \\
\text { for } 2 \text { days. }\end{array}$ & $295^{\circ}$ to $333^{\circ}$ & No drift. \\
\hline 3 & $\begin{array}{l}\text { Cooled rapidly from room } \\
\text { temperature to } 172^{\circ} \text {. }\end{array}$ & $172^{\circ}$ to $311^{\circ}$ & $\begin{array}{l}\text { Upward drift from } 172^{\circ} \\
\text { to } 193^{\circ} \text {. No drift } \\
\text { above } 193^{\circ}\end{array}$ \\
\hline 4 & $\begin{array}{l}\text { Cooled slowly from room } \\
\text { temperature over } 5 \text { days } \\
\text { to } 85^{\circ} \text {. }\end{array}$ & $87^{\circ}$ to $294^{\circ}$ & $\begin{array}{l}\text { Downward drift from } \\
189^{\circ} \text { to } 195^{\circ} \text {. No } \\
\text { drift above } 195^{\circ} \text {. }\end{array}$ \\
\hline 5 & $\begin{array}{l}\text { Cooled from room temper- } \\
\text { ature to } 80^{\circ} \text { and then to } 16^{\circ} \text {. }\end{array}$ & $16^{\circ}$ to $91^{\circ}$ & No drift. \\
\hline 6 & $\begin{array}{l}\text { Cooled from room temper- } \\
\text { ature to } 80^{\circ} \text { and then to } \\
54^{\circ}\end{array}$ & $67^{\circ}$ to $71^{\circ}$ & Do. \\
\hline 7 & $\begin{array}{l}\text { Cooled from room temper- } \\
\text { ature to } 80^{\circ} \text { and then to } \\
55^{\circ} \text {. }\end{array}$ & $55^{\circ}$ to $72^{\circ}$ & Do. \\
\hline
\end{tabular}

TABLE 6. Observed heat capacities of $122^{\circ} \mathrm{F}$ butadiene (90)styrene (10) copolymer $G L-658$

\begin{tabular}{|c|c|c|c|c|c|c|c|c|}
\hline Run & $\mathrm{T}$ & $\mathrm{C}$ & Run & $\mathrm{T}$ & $\mathrm{C}$ & Run & $\mathrm{T}$ & C \\
\hline 2 & $\begin{array}{c}{ }^{\circ} K \\
86.90 \\
96.68 \\
105.71 \\
114.79 \\
123.99 \\
132.71 \\
141.69 \\
153.76 \\
162.53 \\
171.75 \\
179.07 \\
183.82 \\
188.62 \\
193.21 \\
197.23 \\
201.22 \\
212.75 \\
231.34 \\
254.96 \\
279.74 \\
298.54 \\
296.22 \\
298.89 \\
303.65 \\
310.12 \\
316.53 \\
322.88 \\
329.44\end{array}$ & $\begin{array}{c}a b s j \\
{ }^{b} K-1 g-1 \\
0.5793 \\
.6308 \\
.6788 \\
.7277 \\
.7781 \\
.8263 \\
.8761 \\
.9435 \\
.9902 \\
1.036 \\
1.073 \\
1.098 \\
1.133 \\
1.280 \\
1.624 \\
1.684 \\
1.708 \\
1.749 \\
1.809 \\
1.879 \\
1.937 \\
1.928 \\
1.938 \\
1.954 \\
1.975 \\
1.997 \\
2.024 \\
2.041\end{array}$ & 4 & 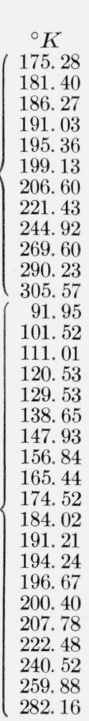 & $\begin{array}{c}a b s j \\
{ }^{\circ} K-1 g-1 \\
1.059 \\
1.083 \\
1.110 \\
1.173 \\
1.553 \\
1.676 \\
1.695 \\
1.727 \\
1.782 \\
1.849 \\
1.910 \\
1.960 \\
.6058 \\
.6563 \\
.7086 \\
.7615 \\
.8103 \\
.8590 \\
.9077 \\
.9551 \\
1.002 \\
1.055 \\
1.125 \\
1.267 \\
1.587 \\
1.689 \\
1.685 \\
1.699 \\
1.730 \\
1.772 \\
1.822 \\
1.887\end{array}$ & 7 & $\begin{array}{l}{ }^{\circ} K \\
16.69 \\
17.82 \\
19.22 \\
20.93 \\
22.94 \\
25.34 \\
28.03 \\
31.59 \\
35.63 \\
39.88 \\
44.39 \\
49.14 \\
71.55 \\
77.90 \\
84.43 \\
91.43 \\
66.94 \\
69.25 \\
71.48 \\
55.87 \\
58.40 \\
60.81 \\
63.11 \\
65.84 \\
68.97 \\
71.95\end{array}$ & $\begin{array}{r}a b s j \\
{ }^{\circ} K-1 g-1 \\
0.0868 \\
.0965 \\
.1078 \\
.1226 \\
.1409 \\
.1624 \\
.1862 \\
.2174 \\
.2498 \\
.2825 \\
.3162 \\
.3521 \\
.4894 \\
.5272 \\
.5662 \\
.6053 \\
.4641 \\
.4770 \\
.4897 \\
.3936 \\
.4101 \\
.4256 \\
.4402 \\
.4566 \\
.4745 \\
.4915\end{array}$ \\
\hline
\end{tabular}

The results of the heat-capacity measurements were used to obtain heat-capacity values at 5-deg intervals from $0^{\circ}$ to $330^{\circ} \mathrm{K}$ (table 7 ). The values at $15^{\circ} \mathrm{K}$ and below were obtained by extrapolation, using the Debye function

$$
C=0.2633 D\left(\frac{88.7}{T}\right)
$$

which was fitted to the experimental results obtained in the temperature range $17^{\circ}$ to $25^{\circ} \mathrm{K}$.

The effect of cooling rate upon the change in enthalpy between $175^{\circ}$ and $210^{\circ} \mathrm{K}$ was computed from the heat-capacity data. The experiments (runs 1 
TABLE 7 . Heat capacity, enthalpy, and entropy of $122^{\circ} F$ butadiene (90)-styrene (10) copolymer G-L658

\begin{tabular}{|c|c|c|c|c|c|c|c|}
\hline$T$ & $C$ & $\left(H_{T}-H_{0}\right)$ & $\left(S_{T}-S_{0}\right)$ & $T$ & $C$ & $\left(H_{T}-I I_{0}\right)$ & $\left(S_{T}-S_{0}\right)$ \\
\hline${ }^{\circ} K$ & $a b s j^{\circ} K^{-1}$ & $a b s j g^{-1}$ & $a b s j^{\circ} K^{-1}$ & ${ }^{\circ} K$ & $a b s j^{\circ} K^{-1}$ & $a b s j g^{-1}$ & $a b s j^{\circ} K^{-1}$ \\
\hline 0 & & & & $17 \overline{5}$ & 1.055 & 97.37 & 1. 067 \\
\hline 5 & 0.0037 & 0.0046 & 0.0012 & 180 & 1. 08 & ..... & $\ldots$ \\
\hline 10 & .0278 & .0719 & .0096 & 185 & 1.11 & $\ldots$ & $\ldots$ \\
\hline 15 & .0729 & .3174 & .0289 & 190 & 1.17 & $-\ldots$ & $-\ldots$ \\
\hline 20 & .1146 & .7859 & .0557 & 195 & 1. 57 & ..... & $\ldots$ \\
\hline 25 & .1595 & 1. 470 & .0860 & 200 & 1. 66 & & \\
\hline 30 & .2037 & 2. 379 & .1191 & 205 & 1. 69 & & \\
\hline 35 & .2449 & 3. 502 & .1536 & 210 & 1. 702 & 145.5 & 1. 315 \\
\hline 40 & .2834 & 4. 823 & .1888 & 215 . & 1. 713 & 154. 0 & 1. 356 \\
\hline 45 & .3208 & 6. 334 & .2244 & 220 & 1. 724 & 162. 6 & 1. 395 \\
\hline 50 & .3588 & 8.034 & .2602 & 225 & 1. 735 & 171.3 & 1. 434 \\
\hline 55 & .3879 & 9.902 & .2958 & 230 & 1. 747 & 180.0 & 1. 472 \\
\hline 60 & .4204 & 11.92 & .3309 & 235 & 1. 758 & 188.7 & 1. 510 \\
\hline 65 & .4518 & 14. 10 & .3658 & 240 & 1. 770 & 197.6 & 1. 547 \\
\hline 70 & .4811 & 16. 44 & .4004 & 245 & 1. 783 & 206. 4 & 1. 584 \\
\hline 75 & .5100 & 18. 91 & .4345 & 250 & 1. 796 & 215.4 & 1. 620 \\
\hline 80 & .5402 & 21.54 & .4684 & 255 & 1.809 & 224.4 & 1. 655 \\
\hline 85 & .5694 & 24.31 & .5020 & 260 & 1.822 & 233.5 & 1. 691 \\
\hline 90 & .5957 & 27. 23 & .5353 & 265 & 1.836 & 242.6 & 1. 726 \\
\hline 95 & .6219 & 30.27 & .5682 & 270 & 1.850 & 251.8 & 1. 760 \\
\hline 100 & .6484 & 33.45 & .6008 & 275 & 1.864 & 261. 1 & 1. 794 \\
\hline 105 & .6752 & 36. 76 & 6331 & 280 & 1.879 & 270.5 & 1. 828 \\
\hline 110 & .7022 & 40.20 & .6651 & 285 & 1.894 & 279.9 & 1.861 \\
\hline 115 & .7298 & 43. 78 & .6970 & 290 & 1. 910 & 289.4 & 1.894 \\
\hline 120 & .7574 & 47. 50 & .7286 & 295 & 1. 925 & 299.0 & 1. 927 \\
\hline 125 & .7849 & 51.35 & .7601 & 298.16 & 1. 936 & 305.1 & 1. 948 \\
\hline 130 & .8122 & 55. 35 & .7914 & 300 & 1. 942 & 308.7 & 1. 960 \\
\hline 135 & .8394 & 59.47 & .8226 & 305 & 1. 958 & 318.4 & 1. 992 \\
\hline 140 & .8665 & 63.74 & .8536 & 310 & 1. 975 & 328.2 & 2. 024 \\
\hline 145 & .8935 & 68.14 & .8844 & 315 & 1.992 & 338.2 & 2. 055 \\
\hline 150 & .9205 & 72.67 & .9152 & 320 & 2. 009 & 348.2 & 2. 087 \\
\hline 155 & .9474 & 77.34 & .9458 & 325 & 2. 026 & 358. 2 & 2. 118 \\
\hline 160 & .9743 & 82.15 & .9763 & 330 & 2. 043 & 368.4 & 2. 149 \\
\hline 165 & 1. 001 & 87.09 & 1.007 & & & & \\
\hline 170 & 1. 028 & 92.16 & 1. 037 & & & & \\
\hline
\end{tabular}

and 3 ) made with the material cooled rapidly yielded 47.61 and 47.75 abs $\mathrm{j} \mathrm{g}^{-1}$, respectively, giving an average of 47.68 abs $\mathrm{j} \mathrm{g}^{-1}$. The result with the polymer

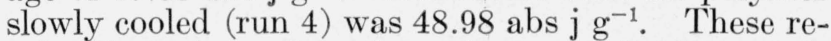
sults show that when the polymer is slowly cooled, the enthalpy change, between the temperature limits given, is greater by about $1.30 \mathrm{abs} \mathrm{j} \mathrm{g}^{-1}$.

The enthalpy values (table 7 ) at 5-deg intervals from $0^{\circ}$ to $330^{\circ} \mathrm{K}$ were obtained in a similar manner as for the $\mathrm{X}-454$ copolymer by evaluating eq 1 . For the temperature interval $175^{\circ}$ to $210^{\circ} \mathrm{K}$, the average enthalpy change for the three experiments $(1,3$, and 4) was used in constructing the table. No attempt was made to evaluate the enthalpies at other temperatures within this interval.

The entropy values were evaluated in a similar manner as were those of $\mathrm{X}-454$ copolymer. These are given in table 7 . The entropy change over the temperature interval $175^{\circ}$ to $210^{\circ} \mathrm{K}$ used in the computations is the average of the three experiments previously mentioned.

\subsection{Reliability of Results}

The reliability of the heat-capacity measurements with the copolymers is difficult to evaluate because of the nonreproducibility of the physical state. Campbell and Allen [12] have shown in photomicrographs similarity in spherulite formation when the polymer was not raised too far above its melting temperature and recrystallized. The scattering in the heatcapacity results of $\mathrm{X}-454$ copolymer does not seem to support this, however. The heat-capacity measurements with more normal materials $[5,8]$ in a similar calorimeter yielded results considered to have an error of 0.2 percent. ${ }^{4}$ The results with the X-454 copolymer show the heat capacities of the two series of experiments to differ as much as 1.2 percent just below the glass-transformation temperature. Within the same series of experiments, in which the material has been treated very similarly, the results are within 0.2 percent, except near the transformation temperature. The results above the crystallization temperature (that is, above $285^{\circ} \mathrm{K}$ ) in the amorphous region are believed to have the error of 0.2 percent. Below the glass-transformation temperature to $50^{\circ} \mathrm{K}$ the error of the results in the same series of experiments is considered to be 0.3 percent. Below $50^{\circ} \mathrm{K}$, the error increases to several percent at $17^{\circ} \mathrm{K}$.

The results with the GL-658 copolymer show as much as 1-percent scattering in the temperature range $165^{\circ} \mathrm{K}$ to the glass-transformation temperature. Between $90^{\circ}$ and $165^{\circ} \mathrm{K}$ the results are essentially the same within \pm 0.2 percent, regardless of the heat treatment. Above the glass-transformation temperature at which the heat-capacity results lie on a smooth curve, the results are considered to have an error of 0.2 percent. Between $50^{\circ}$ and $165^{\circ} \mathrm{K}$, the error is believed to be 0.3 percent, and between $165^{\circ} \mathrm{K}$ and the glass-transformation temperature, to be 0.5 to 1 percent. Below $50^{\circ} \mathrm{K}$ the error increases to several percent similar to the $\mathrm{X}-454$ copolymer.

Except for the transition intervals, the tabulated (tables 4 and 7 ) enthalpy and entropy for the two copolymers were obtained, as previously shown, from the smoothed heat capacities. These thermal quantities are dependent upon the accuracy of the heat capacity from which they were evaluated. Considering the various sources of inaccuracy, the error in the tabulated values of these quantities is believed to be 0.5 percent.

\section{Discussion}

The results of these experiments show that the increase in the polymerization temperature from $41^{\circ}$ to $122^{\circ} \mathrm{F}$ eliminated crystallization effects in the $90 / 10$ butadiene-styrene copolymer. This behavior, in which the crystallizability of polymers is increased with decreasing polymerization temperatures, has been observed by other investigators. Beu, et al. [13] and Beu [14], using an X-ray method, found such a behavior in the crystallinity of stretched polybutadienes and butadiene-styrene copolymers prepared at temperatures from $-20^{\circ}$ to $+55^{\circ} \mathrm{C}$. Lucas, et al. [15], using a dilatometer method, studied relative crystallizability and molecular regularity in polybutadienes, polychloroprenes, and butadiene-styrene copolymers prepared at temperatures ranging from $-33^{\circ}$ to $+50^{\circ} \mathrm{C}$, and found a similar behavior in the crystallizability of these polymers. More recently, Campbell and Allen [12] used a polarizing microscope

4 For these experiments a true probable error cannot be computed statistically. The values given are estimates reached by examining contributions to the inaccuracy from all known sources. The authors estimate that there is an equal chance that the error is no larger than that indicated. 
to show greater crystallizability in polybutadienes prepared at lower temperatures. They found $41^{\circ} \mathrm{F}$ $90 / 10$ butadiene-styrene copolymer to show a small crystallinity.

Bekkedahl and Matheson [10] measured the heat capacity of natural rubber and reported a fairly sharp melting point, giving the melting temperature as $284^{\circ} \mathrm{K}$. Wood and Bekkedahl [16] found the crystallization temperature of unvulcanized natural rubber to extend from $220^{\circ}$ to $290^{\circ} \mathrm{K}$. Their measurements also show the melting temperature to depend upon the crystallization temperature. The results of the measurements with the $\mathrm{X}-454$ copolymer reported herein show the crystallization temperature to extend from $210^{\circ}$ to $285^{\circ} \mathrm{K}$, with no indication of any sharp melting temperature. There is, however, at about $250^{\circ} \mathrm{K}$ a maximum (fig. 1) in the heat capacity. In recent unpublished heatcapacity investigations at the Bureau with $41^{\circ}$ and $122^{\circ} \mathrm{F}$ polybutadienes, the crystallization temperature ranges were found to be from $200^{\circ}$ to $295^{\circ} \mathrm{K}$ and $200^{\circ}$ to $270^{\circ} \mathrm{K}$, respectively.

In the heat-capacity experiments by Bekkedahl and Matheson [10] the glass-transformation temperature was reported to be $199^{\circ} \mathrm{K}$. Thermal expansion measurements, in which the coefficient of thermal expansion rises steeply with temperature at the glass-transformation temperature in a similar manner as the heat-capacity curve, show glass transformation in natural rubber to occur at $200^{\circ} \mathrm{K}$ [17]. Ferry and Parks [18] investigated the heat capacity and thermal expansion of polyisobutylene and found the glasstransformation temperature in both measurements to be $197^{\circ} \mathrm{K}$. As pointed out by Kauzmann [19], this indicates a close alliance of motions in polymers involving energy and volume. Also, glass transformation as observed in heat-capacity and thermal- expansion measurements is closely associated with the brittle-point temperature, below which rubber polymers lose rubber-like elasticity. Similarly, dielectric-relaxation time [19] is shown to increase steeply as temperature is lowered through the glasstransformation temperature. There are many suggestions [20, 21, 22] as to how molecular structure in the polymer affects the glass-transformation temperature. The size of the side groups, symmetry of the polymeric units, degree of cross-linking, and ease of rotation about the carbon-carbon bonds as might be influenced by the intramolecular structure and neighboring molecules are some of the factors that seem to affect the glass-transformation temperature. The transformation temperature in styrene-divinyl benzene copolymers [21] has been shown to increase when the number of monomer units between crosslinks becomes less than 300. The crystallization process would be expected to have a similar effect [21], if the degree of crystallization is such that the number of monomer units between crystallites becomes smaller than the above figure. The heatcapacity measurements [10] with natural rubber show that this transformation temperature is higher when the material is crystallized, although attention has not been called previously to this fact. The results with the $\mathrm{X}-454$ copolymer show a similar rise in the transformation temperature when the sample was annealed. As previously pointed out, the results are, however, dependent somewhat upon the time allowed before temperature measurement. On the other hand, the experiments with the $122^{\circ} \mathrm{F}$ copolymer, which does not crystallize, seem to show that the steep increase in the heat-capacity curve occurs a few degrees lower in the slowly cooled experiments. In comparing the glass-transformation temperatures, the experimental results with the two

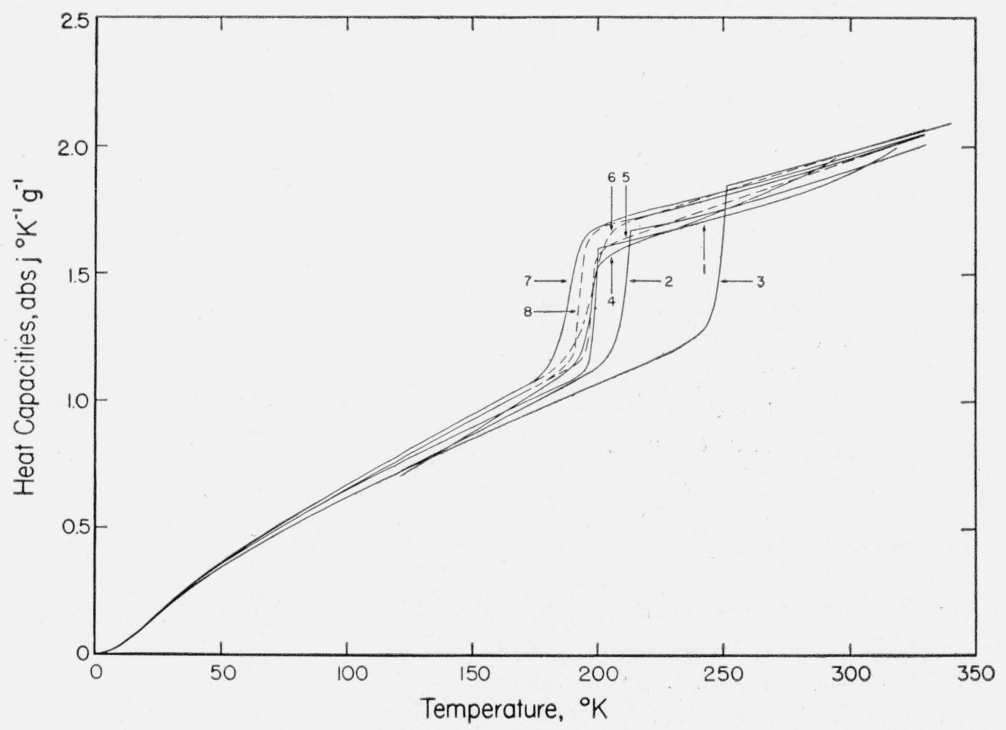

Figure 3. Comparison of the heat-capacity curves of various polymers.

1, Natural rubber [10]; 2, GR-S [2]; 3, Hycar O. R.-15 [1]; 4, polyisobutylene [19]; $5,41^{\circ} \mathrm{F} 90 / 10$ butadiene-styrene copolymer; $6,41^{\circ} \mathrm{F}$ polybutadiene; $7,122^{\circ} \mathrm{F}$ polybutadiene, and $8,122^{\circ}$ F $90 / 10$ butadiene-styrene copolymer. 
copolymers indicate that the change in the polymerization temperature from $122^{\circ} \mathrm{F}\left(50^{\circ} \mathrm{C}\right)$ to $41^{\circ}$ $\mathrm{F}\left(5^{\circ} \mathrm{C}\right)$ raised the transformation temperature from $193^{\circ}$ to $200^{\circ} \mathrm{K}$. This behavior is similar to that found with the recently investigated $122^{\circ}$ and $41^{\circ} \mathrm{F}$ polybutadienes, in which the glass-transformation temperatures obtained are $187^{\circ}$ and $195^{\circ} \mathrm{K}$, respectively. These results seem accordant on the basis that a higher polymerization temperature yields a polymer of lower regularity [12, 13, 14, 15] and a more open intermolecular structure to permit greater ease in the rotation of the polymer segments [21]. As previously mentioned, crystallization increases the glass-transformation temperature, and the lowering of the polymerization temperature increases the crystallizability. These effects are all consistent with the experimental results.

Tuckett [22] and Überreiter [23] have shown that in styrene-butadiene copolymers the styrene hinders free rotation, and that the increase in the boundstyrene content raises the glass-transformation temperature. The glass-transformation temperature $195^{\circ}$ and $187^{\circ} \mathrm{K}$ for the $41^{\circ}$ and $122^{\circ} \mathrm{F}$ polybutadienes, $200^{\circ}$ and $193^{\circ} \mathrm{K}$ for the $41^{\circ}$ and $122^{\circ} \mathrm{F}$ butadiene-styrene (8.58 percent) copolymers reported here, and $237^{\circ} \mathrm{K}$ very recently obtained at the Bureau for the $122^{\circ} \mathrm{F}$ butadiene-styrene (42.98 percent) copolymer are in conformity with the results of the above investigators.

The heat-capacity curves for polyisobutylene [18], natural rubber [10], Hycar O. R.-15 [1], GR-S [2], $41^{\circ}$ and $122^{\circ} \mathrm{F}$ polybutadienes, and $41^{\circ}$ and $122^{\circ} \mathrm{F}$ $90 / 10$ butadiene-styrene copolymers are compared in figure 3. It is interesting to note that the heat capacities per unit mass for these polymers lie within a narrow band. The heat capacities of the two copolymers reported merge into a single curve below the glass-transformation temperature; percentage wise, however, the curves are not quite the same as shown by tables 4 and 7 . The experimental values above the transformation temperature for the two copolymers differ by about 0.1 percent at $295^{\circ} \mathrm{K}$, increasing to about 0.7 percent at $330^{\circ} \mathrm{K}$. The two polybutadienes, previously mentioned, show similar behavior. The glass-transformation temperatures of the various polymers are compared in the figure, showing Hycar 0. R.-15 [1] to have the highest transformation temperature.
The authors are grateful to W. Bruenner and M. L. Reilly for assisting with some of the experimental work and calculations, to M. Tryon for purifying the polymer samples, and to R. A. Paulson for the chemical analysis of the polymers.

\section{References}

[1] N. Bekkedahl and R. B. Scott, J. Research NBS 29, 87 (1942) RP 1487.

[2] R. D. Rands, Jr., W. J. Ferguson, and J. L. Prather, J. Research NBS 33, 63 (1944) RP1595.

[3] J. M. Goppel and J. J. Arlman, Appl. Sci. Research, A1, 462 (1949).

[4] R. B. Scott, C. H. Meyers, R. D. Rands, Jr., F. G. Brickwedde, and N. Bekkedahl, J. Research NBS 35, 39 (1945) RP1661.

[5] G. T. Furukawa, D. C. Ginnings, R. E. McCoskey, and R. A. Nelson, J. Research NBS 46, 195 (1951) RP2191.

[6] H. F. Stimson, J. Research NBS 42, 209 (1949) RP1962.

[7] H. J. Hoge and F. G. Brickwedde, J. Research NBS 22, 351 (1939), RP1188.

[8] G. T. Furukawa, R. E. MeCoskey, and G. J. King, J. Research NBS 47, 256 (1951) RP2251.

[9] R. W. Laundrie, Butadiene-styrene copolymers for refractive index studies, University of Akron-Government Laboratories, AU-725, Project P 100.74 August $12,1949$.

[10] N. Bekkedahl and H. Matheson, J. Research NBS 15, 503 (1935) RP844.

[11] Tables of Lagrangian Interpolation coefficients (Columbia University Press, New York, N. Y., 1944).

[12] H. N. Campbell and M. D. Allen, Ind. Eng. Chem. 43, 413 (1951).

[13] K. E. Beu, W. B. Reynolds, C. F. Fryling, and H. L. MeMurry, J. Polymer Sci. 3, 465 (1948).

[14] K. E. Beu, J. Polymer Sci. 3, 801 (1948).

[15] V. E. Lucas, P. H. Johnson, L. B. Wakefield, B. L. Johnson, Ind. Eng. Chem 41, 1629 (1949).

[16] L. A. Wood and N. Bekkedahl, J. Research NBS 36, 489 (1946). RP1718.

[17] N. Bekkedahl, J. Research NBS 13, 411 (1934) RP717.

[18] J. D. Ferry and G. S. Parks, J. Chem. Phys. 4, 70 (1936).

[19] W. Kauzmann, Chem. Rev. 43, 219 (1948).

[20] K. Überreiter, Kolloid-Z. 102, 272 (1943).

[21] H. Mark and G. S. Whitby, Scientific progress in the field of rubber and synthetic elastomers (Interscience Publishers, Inc., New York, N. Y., 1946).

[22] R. F. Tuckett, Trans. Faraday Soc. 38, 310 (1942).

[23] K. Überreiter, Z. angew. Chem. 53, 247 (1940).

Washington, June 9, 1952. 